\title{
G035 STRUCTURAL CHARACTERIZATION OF REDUCED AND CHEMICALLY SUBSTITUTED DERIVATIVES OF THE MN CLUSTER IN THE PHOTOSYNTHETIC OXYGEN EVOLVING COMPLEX
}

Pamela_J_Riggs, a Rui Mei,b Charles F. Yocum, a,b and James E. Penner-Hahna

Department of Chemistry, $a$ Department of Biology, $b$ University of Michigan, Ann Arbor, MI 48109.

Water oxidation in Photosystem II of higher plants is catalyzed by the oxygen evolving complex (OEC) which contains 4 essential Mn ions, $\mathrm{Ca}^{2+}$, and $\mathrm{Cl}^{-}$as cofactors. Despite its importance in the photosynthetic process, the geometry and oxidation state of the cluster during its catalytic cycle have yet to be unambiguosly determined. We have used X-ray Absorption Spectroscopy (XAS) in an effort to elucidate the structure of the native state. It has been proposed that hydroxylamine acts as a 2 electron reductant in the dark to form a state formulated $S_{-1 .}$. [1] The absorption edge shift we observe in the dark of samples treated with hydroxylamine $(100 \mu \mathrm{M}$, $3 \mathrm{~min}$.) is consistent with this interpretation. Hydroquinone $(200 \mu \mathrm{M}, 30$ min.) induces an edge shift in the dark that indicates the presence of 1-2 $\mathrm{Mn}$ (II) not present in the control $\left(\mathrm{S}_{1}\right)$ state. Both of these dark reductions can be completely reversed with steady state illumination for 3 minutes, consistent with the observed minimal activity loss.

Past EXAFS analysis of the control $S_{1}$ state indicated the presence of a shell of low $\mathrm{Z}$ ligands @ $1.9 \AA, 2-3 \mathrm{Mn}-\mathrm{Mn}$ vectors at $2.7 \AA$, and $1 \mathrm{Mn}-\mathrm{Mn} / \mathrm{Ca}$ vector at $3.3 \AA$.[3] The hydroquinone reduced sample has a new shell of ligands at circa $2.1 \AA$, half the number of $\mathrm{Mn}-\mathrm{Mn}$ vectors at $2.7 \AA$ and no interaction at 3.3A. These changes are completely reversed with illumination. Changes in the EXAFS of the hydroxylamine treated sample will also be

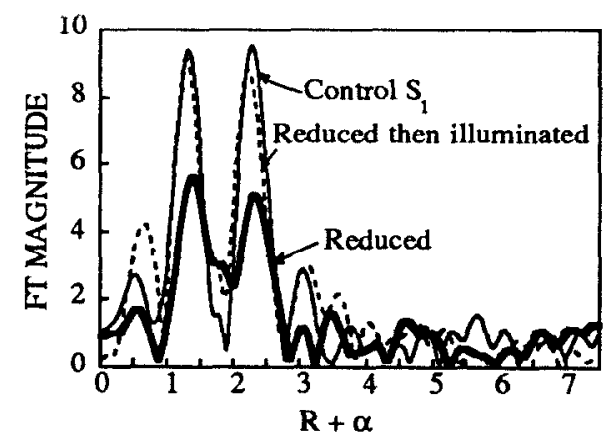

FIGURE 1: EXAFS spectra of control, hydroquinone reduced and reduced then illuminated. discussed.

The identity of the $3.3 \AA$ scatterer has yet to be resolved. The disappearance of this feature with reduction and its reappearance upon the photoxidation of the $\mathrm{Mn}$ may argue for a $\mathrm{Mn}-\mathrm{Mn}$ interaction. In addition, we have recently finished a study in which $\mathrm{Sr}^{2+}, \mathrm{Dy}^{3+}$ and $\mathrm{La}^{3+}$, replace $\mathrm{Ca}$. None of these substitutions cause a significant change in the $3.3 \AA$ peak.

1) H. Kretschmann, et al. Biochim. Biophs. Acta, 1059, 208-214 (1991).

2) P. Riggs, et al. J. Am. Chem. Soc., 114, 10650-20651 (1992).

3) J. Penner-Hahn et al. J. Am. Chem. Soc. 112, 2549-2557 (1990). 